\title{
Perspectivas de ensino nos cursos técnicos: experiências de professores nas aulas remotas mediadas por Jamboard
}

\author{
Teaching perspectives in technical courses: experiences of teachers in remote classes \\ mediated by Jamboard
}

\section{Perspectivas docentes en cursos técnicos: experiencias de profesores en clases remotas mediadas por Jamboard}

\section{Resumo:}

$\mathrm{O}$ advento da pandemia do novo coronavírus trouxe ao mundo uma mudança de paradigmas em todos os setores da vida humana. Na educação não foi diferente e as escolas tiveram emergencialmente que readaptar as suas atividades. Este artigo tem por objetivo apresentar as experiências de professores dos cursos técnicos subsequentes em eletrotécnica e enfermagem em aulas remotas mediada pela ferramenta Jamboard, tendo como justificativa o fato do predomínio da avaliação se dar nas atividades online que contribui para a formação de seus alunos e professores que atuam nessa etapa de educação, discutindo a ferramenta e suas potencialidades para o ensino e aprendizagem dos alunos. A metodologia da pesquisa foi de caráter qualitativo, do tipo estudo de caso, e a obtenção dos dados foi através da observação e análise do desenvolvimento das e-atividades construídas pelos alunos. Na realidade, foi demandada a aproximação dos professores e alunos à realidade online, relacionado à organização, seleção de recursos, preparação e avaliação de e-atividades de aprendizagem significativa nessa nova normalidade que se estabelece. Mas ninguém, nem mesmo os professores que já adotavam ambientes online nas suas práticas imaginava que seria necessária uma mudança tão rápida e emergencial, devido à expansão do coronavírus. A experiência trouxe mecanismos para vivenciar o ensino remoto utilizando ferramentas tecnológicas por meio de metodologias ativas, ressaltando reflexões entre o momento presencial e o remoto. Valorizando o ensino que envolve professores e alunos em um ambiente pedagógico que potencializa a forma de aprender para redimensionar o processo de ensino-aprendizagem.

Palavras-chave: Ensino Remoto; Tecnologias Digitais; Ferramenta Jamboard.

\footnotetext{
Abstract:

${ }^{1}$ Mestre em Educação pela Universidade Federal de Sergipe (UFS). Professor Efetivo EBTT do Instituto Federal de Educação, Tecnológica de Alagoas, Campus Maceió (IFAL). E-mail: andre.melo@ifal.edu.br $\underline{\text { IORCID: }}$ https:/orcid.org/0000-0002-3565-4034

${ }^{2}$ Doutorado em Engenharia Elétrica pela (UNICAMP) - Universidade Estadual de Campinas. Professor Efetivo do Instituto Federal de Alagoas Campus Maceió (IFAL). E-mail: givaldo.oliveira@ifal.edu.br ORCID: https://orcid.org/0000-0002-7525-3526

${ }^{3}$ Mestre em Ensino na Saúde pela Universidade Federal de Alagoas (FAMED/UFAL). Professora Efetiva EBTT do Instituto Federal de Educação, Tecnológica de Alagoas, Campus Benedito Bentes (IFAL). E-mail: patricia.florencio@ifal.edu.br ORCID: $\underline{\text { https://orcid.org/0000-0002-8449-0750 }}$
}

Revista Devir Educação, Lavras-MG. Edição Especial, p.206-226, Set./2021. 
The advent of the new coronavirus pandemic has brought a paradigm shift in all sectors of human life to the world. Education was no different and schools had to adapt their activities on an emergency basis. This article aims to present the experiences of teachers of technical courses in electrotechnics and nursing in remote classes mediated by the Jamboard tool, justifying the fact that the predominance of assessment occurs in online activities that contributes to the training of their students and teachers. who work in this stage of education, discussing the tool and its potential for teaching and learning students. The research methodology was qualitative, of the case study type, and obtaining the fori data through observation and analysis of the development of the e-activities constructed by the students. In reality, the approach of teachers and students to the online reality was demanded, related to the organization, selection of resources, preparation and evaluation of e-activities of significant learning in this new normality that is established. But no one, not even teachers who already adopted online environments in their practices, imagined that such a rapid and emergency change would be necessary, due to the expansion of the coronavirus. The experience brought mechanisms to experience remote teaching using technological tools through active methodologies, emphasizing reflections between the face-to-face and the remote moment. Valuing teaching that involves teachers and students in a pedagogical environment that enhances a way of learning to resize the teaching-learning process.

Keywords: Remote Teaching; Digital Technologies; Jamboard tool.

\section{Resumen}

El advenimiento de la nueva pandemia de coronavirus ha traído al mundo un cambio de paradigma en todos los sectores de la vida humana. En educación no fue diferente y las escuelas tuvieron que readaptar sus actividades con urgencia. Este artículo tiene como objetivo presentar las experiencias de docentes de posteriores cursos técnicos en ingeniería eléctrica y enfermería en clases a distancia mediadas por la herramienta Jamboard, justificando el hecho de que el predominio de la evaluación se da en actividades online que contribuyen a la formación de sus alumnos y docentes que trabajar en esta etapa de la educación, discutiendo la herramienta y su potencial para la enseñanza y el aprendizaje de los estudiantes. La metodología de investigación fue de carácter cualitativo, del tipo estudio de caso, y la recolección de datos fue a través de la observación y análisis del desarrollo de las eactividades construidas por los estudiantes. En realidad, se exigió el acercamiento de docentes y estudiantes a la realidad online, relacionado con la organización, selección de recursos, preparación y evaluación de e-actividades de aprendizaje significativas en esta nueva normalidad que se establece. Pero nadie, ni siquiera los profesores que ya estaban adoptando entornos online en sus prácticas, imaginaban que sería necesario un cambio tan rápido y de emergencia, debido a la expansión del coronavirus. La experiencia trajo mecanismos para vivir la enseñanza a distancia utilizando herramientas tecnológicas a través de metodologías activas, destacando reflexiones entre el momento presencial y el remoto. Valorar una enseñanza que involucre a docentes y alumnos en un entorno pedagógico que potencie la forma de aprender para redimensionar el proceso de enseñanza-aprendizaje.

Palabras clave: Enseñanza remota; Tecnologías digitales; Herramienta Jamboard. 


\section{Introdução}

$\mathrm{O}$ advento da pandemia do coronavírus trouxe ao mundo uma mudança de paradigmas em todos os setores da vida humana. Uma nova cepa de coronavírus, denominada SARS-Cov2 (Síndrome Respiratória Aguda Grave do Coronavírus 2) foi detectada na China, causadora da COVID-19. Nunca tantos países ao redor do mundo fecharam escolas públicas, Institutos Federais e Universidades ao mesmo tempo e pelo mesmo motivo, assim o intuito do artigo surgiu a partir dos impactos causados pelo coronavírus na educação em todo mundo.

O contexto da educação mudou, desta forma, as escolas tiveram emergencialmente que se readaptar às suas novas atividades. As Instituições da Rede Federal de Ensino e Universidades Federais de Ensino em decorrência ao que foi sugerido pelo Ministério da Educação (MEC), atenderam à recomendação da Organização Mundial da Saúde (OMS) e mudaram suas atividades presenciais para atividades remotas, evitando, assim, as aglomerações e o risco de disseminação do Coronavírus nas mais de 600 unidades em todo o País. Nessa direção houve o fechamento de inúmeras instituições presencialmente tanto públicas (Federais, Estaduais e Municipais) como privadas em todo o país, impactando assim na vida de milhões de servidores e alunos.

Com a suspensão das atividades presenciais, de todas as instituições de ensino, o que fazer? Diante disso, gerou uma nova estratégia de participação de professores e alunos migrarem para uma nova realidade, no formato online, transferindo e transpondo metodologias e práticas pedagógicas de aprendizagem, que eles se debruçassem sobre novas práticas de ensino. Assim, teve-se que aprender a ensinar e a colaborar remotamente, construindo por meio das tecnologias digitais embasadas e justificadas pelo "novo normal" em uma sala de aula a distância.

Diante desse cenário o presente artigo relata vivências dos professores nas aulas remotas, nos cursos técnicos subsequentes de Eletrotécnica e Enfermagem, analisando a prática e o uso de tecnologias nas ações pedagógicas com a finalidade de difundir ferramentas nas aulas, favorecendo uma aprendizagem interativa e multidisciplinar, de forma a mostrar que é possível usar uma contextualização diferenciada no ensino. A escolha do tema deu-se devido à necessidade de investigar como os professores envolvidos na pesquisa abordam a 
ferramenta tecnológica Jamboard ${ }^{4}$ e suas potencialidades para o ensino, perante as aplicações em seus diversos conhecimentos construídos na interação entre os professores e alunos nas disciplinas envolvidas nos momentos síncronos $^{5}$ e assíncronos $^{6}$, mediado por metodologias ativas. A metodologia utilizada foi de caráter qualitativo, do tipo estudo de caso, e a obtenção dos dados foi através da observação e análise do desenvolvimento das construções dos alunos.

O objetivo é favorecer um ambiente contextualizado nas aulas remotas mediadas pela ferramenta Jamboard no ensino técnico do Instituto Federal de Ensino de Alagoas (IFAL), a partir de abordagem remota no contexto de cultura digital e rever a dinâmica de funcionamento da aprendizagem e os principais resultados e a construção do conhecimento permanentemente (re)construídos, promovendo a interação coletiva, o diálogo com seus alunos e professores e apontar novas práticas e técnicas de ensino que possam aproximar o professor das ferramentas interativas digitais no curso de Eletrotécnica e Enfermagem.

A referida pesquisa centrou-se nas seguintes problemáticas: A pandemia traz consigo diversos desafios para a educação, o processo de ensino-aprendizagem é impactado por esse cenário nos cursos técnicos subsequentes de Eletrotécnica e Enfermagem? E assim, como avaliar no processo de ensino e aprendizagem nos cursos técnicos nessas novas condições? Por isso, é importante compor as verificações do ensino remoto com diferentes abordagens e práticas quantitativas e qualitativas, podendo-se incluir, por exemplo:

1. Participação nas atividades propostas em fóruns; 2. Cumprimento de tarefas em ambientes virtuais de aprendizagem (Classroom); 3. Desenvolvimento de projetos colaborativos online; 4. Atividade com Rubricas; 5. Gamificação; 6. Testes objetivos com a ferramenta Google Formulário; 7. Apresentações Orais; 8. Sala de Aula Invertida; 9. Compartilhar experiências e objetivos de aprendizagem; 10. Atendimento ao aluno(a).

Entende-se que há de fato uma cultura escolar que se manifesta vivamente não só dos objetos, mas, também, das práticas empreendidas com esses e através desses objetos, que precisam ser investigados a partir desse suporte material, enfatizando na interpretação objetiva, diante das atividades escolares. Esse presente artigo apresenta uma análise que

\footnotetext{
${ }^{4} \mathrm{O}$ Jamboard é um quadro interativo desenvolvido pelo Google, como parte da família G-Suíte. O Jamboard é uma tela inteligente. Uma ferramenta interativa e motivadora com prática de interação aluno/professor com atividades online, apresentação de conteúdos e compartilhamento de material.

${ }^{5}$ As aulas síncronas são aquelas que acontecem ao vivo. Com alunos(a), professor(a) numa mesma sala virtual. Interagindo por meio de som, imagem, chat online, Atividade e apresentação de conteúdo. ${ }^{6}$ Os momentos assíncronos são aqueles em que o professor(a) sobe em alguma plataforma virtual um arquivo com suas explicações sobre um determinado tema.
} 
observa e rememora experiências vivenciadas na utilização de práticas na cultura escolar articulada nos momentos síncronos e assíncronos das aulas remotas pelos professores pesquisadores envolvidos, nas atividades aplicadas nos cursos técnicos nas unidades curriculares da pesquisa em estudo.

Isso mostra-se particularmente desafiador no caso dos cursos de Eletrotécnica e de Enfermagem na modalidade subsequente da Instituição de Ensino, proporcionando assim à educação algo que ninguém em nenhum momento imaginou lecionar aulas de forma remota para alunos na modalidade subsequente "técnico" de modo aligeirado, forçando portanto a uma logística de capacitação de professores e de alunos para trabalhar com Tecnologia da informação e comunicação (TIC) e metodologias ativas, acessibilidade digital e reordenamento das unidades curriculares.

Entretanto deve-se encontrar outras dimensões para a realização das atividades que agora têm acontecido de forma remota que proporcionam caminhos na história da educação. Os paradigmas encontrados no objeto da pesquisa direcionando-se o IFAL a partir de dentro de suas formas de organização e das ações empreendidas por todos os alunos envolvidos, nas ações e experiências com a cultura escolar: em valores, saberes, práticas, estratégias, enfim, um repertório de atividades sociais e culturais específicas de natureza escolar que alunos, professores, outros profissionais da escola, os responsáveis e a comunidade envolvidos nessa cultura realizam neste âmbito, em que tipicamente os alunos interagem em um grande mural virtual com a utilização da ferramenta Jamboard.

\section{Delineamento e organização do ambiente digital mediado pela ferramenta Jamboard nas atividades remotas}

O Jamboard é um quadro interativo que se conecta ao ecossistema de ferramentas de busca, em especial o G-Suíte (pacote Google para educação) colaborativo com uma tela inteligente que torna a aprendizagem visível e acessível para todos os colaboradores na sessão do $\mathrm{Jam}^{7}$. Além disso, é fácil apresentar os Jams em tempo real no Google Meet, o que permite fazer compartilhamentos deles, criados por qualquer pessoa ou equipe e explorar conexões deles com o mundo real. Os professores podem incluir todos os alunos com limite de 20 Jams no processo de construção/interação no ambiente de trabalho para aprendizagem colaborativa

\footnotetext{
${ }^{7}$ Cada quadro branco ou frame do Jamboard.
} 
e interativa, seja para trabalhos na sala de aula tradicional, para seminários em grupo ou pelo ensino remoto. O Jamboard permite que equipes até mesmo em locais muito distantes discutam e interajam ideias e conhecimentos e as salve na nuvem para acesso em qualquer dispositivo. Neste contexto de pandemia de Covid-19, os autores trazem seus relatos de experiências vivenciadas, no uso da ferramenta Jamboard, para realização das e-atividades ${ }^{8}$ com os alunos dos cursos de Eletrotécnica e de Enfermagem na modalidade subsequente e consequentemente todos os envolvidos, professores e alunos, podem participar facilmente usando um tablet, smartphone, notebook, computador, através das e-atividades que forem construídas colaborativamente ou individualmente.

Nos cursos envolvidos é utilizada metodologia ativa e a ferramenta Jamboard, pertencente ao Google Education, e a plataforma Classroom para postagem de material didático, construção de documentos, fórum, atividade e avaliação no momento assíncrono. As formas de entender a construção do conhecimento e os conteúdos das unidades curriculares, apresentados na Figura 1.

1. Acesse o Jamboard clicando nos 9 pontos no ícone do G Suíte acima.

2. Ao selecionar o ícone do G suíte, desça a barra de rolagem até encontrar a ferramenta Jamboard e clique.

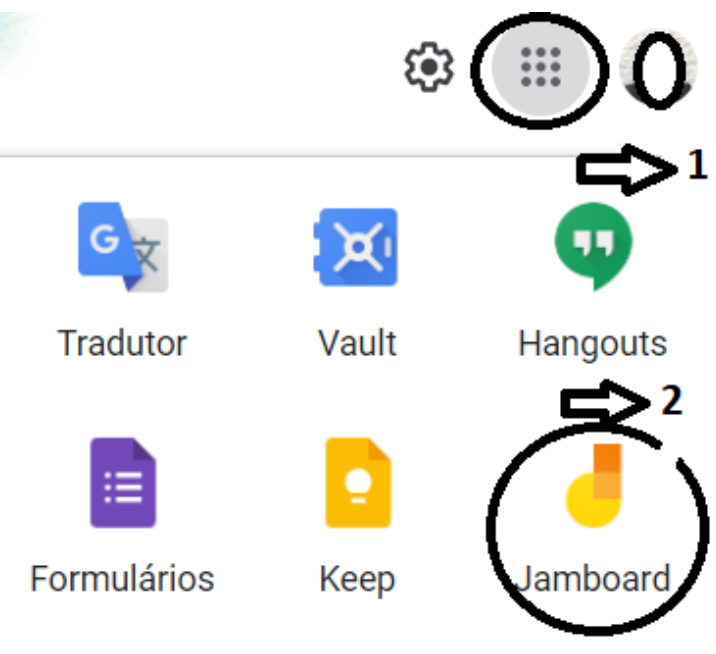

Figura 1 - Ícone da ferramenta Jamboard.

Fonte: Autoria própria (2021).

Na Figura 1, mostra uma variedade de ícones da Google Education, e o ícone selecionado em estudo a ferramenta Jamboard que é uma lousa digital interativa online que pertence às ferramentas da Google, através dessa lousa, você pode criar aulas interativas, salvar trabalhos na nuvem automaticamente, salvar em PDF, compartilhar tela com os alunos

\footnotetext{
${ }^{8}$ e-atividades são consideradas todas as atividades que se encontram em ambientes virtuais de aprendizagem Salmon (2004).
}

Revista Devir Educação, Lavras-MG. Edição Especial, p.206-226, Set./2021. 
através do Google Meet, permitindo que eles editem o frame (quadro) colocando ideias e trocando opiniões sobre determinado assunto das unidades curriculares em estudo, e assim nas aulas síncronas ou assíncronas use-se a ferramenta de reconhecimento de formas e de escrita e fácil de ler, interagir, desenhar e pesquisar, como se estivesse usando um quadro branco.

A Figura 2 mostra o ambiente de interação com a ferramenta Jamboard onde os participantes inserem imagens, caixas de texto, pesquisa online, plano de fundo, nota autoadesiva, caneta, laser, arquivo em PDF e pincel. Todos podem colaborar e realizar um trabalho em equipe ou individual, basta acessar o link disponibilizado pelo professor.

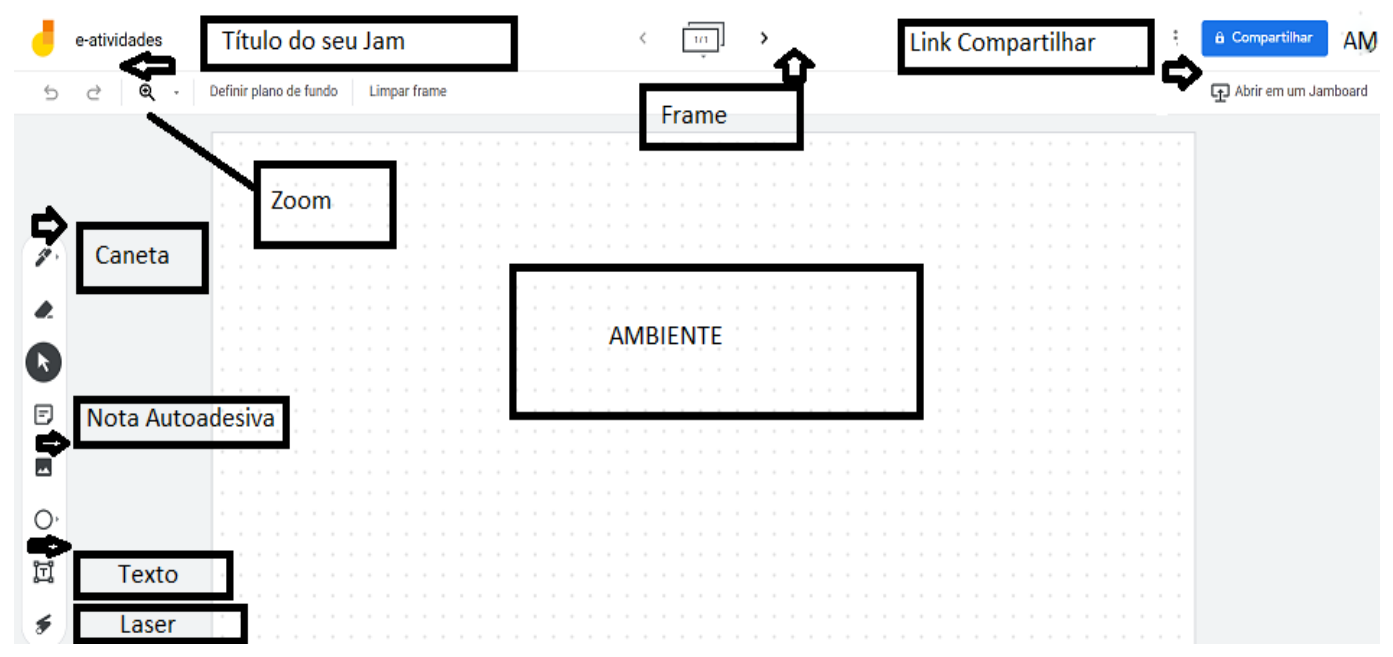

Figura 2 - Ambiente de interação online com a ferramenta Jamboard. Fonte: Autoria própria (2021).

Diante disso, o plano do curso deve estar articulado com as propostas pedagógicas que envolvem os alunos em seu aprendizado, além disso, é oportuno apontar uma discussão sobre a imersão do ensino online mediado por metodologias ativas para construção e reconstrução do conhecimento com o ambiente online Jamboard nas suas e-atividades com os alunos e professores na interação com as unidades curriculares dos cursos envolvidos e pelas experiências vivenciadas pelos autores, partindo da abordagem de uma aprendizagem significativa - é significativa, quando se relacionam a outras ideias que funcionam como âncoras (AUSUBEL, 1968).

\section{Preparação de e-atividades}

Revista Devir Educação, Lavras-MG. Edição Especial, p.206-226, Set./2021. 
Em síntese ao que foi apresentado por Salmon (2004), entende-se que as e-atividades são consideradas todas as atividades que se encontram em ambientes virtuais de aprendizagem, sendo necessário que se produzam de forma adequada pedagogicamente e envolventes para os alunos, buscando a máxima utilização das ferramentas da tecnologia digital que estejam disponíveis e acima de tudo que sejam colaborativas, interativas e que estimulem o raciocínio crítico do aluno.

Deve-se, portanto, em salas de aulas virtuais, segundo Moreira, Henriques e Barros (2020), socializar o grupo, induzir e moderar a negociação e a partilha de ideias, facilitar o acesso à informação e ao conhecimento e auxiliar no processo de investigação e desenvolvimento do pensamento crítico.

Segundo Martins e Almeida (2020) as tecnologias podem potencializar as práticas pedagógicas colaborativas, deixando pistas de que não se trata apenas da inclusão das tecnologias em ambiente escolar, mas sim de uma transformação de pensamento sobre o ato educativo. Sendo assim, as e-atividades podem trazer a interatividade, a colaboração, o estar junto mesmo a distância, produzindo conjuntamente conhecimento.

As e-atividades referem-se às diferentes ações que os alunos realizam em interação com os conteúdos e as indicações que lhes são oferecidas. Para se produzirem e-atividades bem estruturadas, deve-se tirar o maior aproveitamento dos recursos existentes e das tecnologias digitais da web social. Se essas atividades forem apresentadas, realizadas ou transferidas online poderão ser consideradas e-atividades.

Este estudo, além de relatar uma experiência inovadora em sala de aula online não é um repositório de conteúdos digitais, é um espaço ativo, na qual foi possível possibilitar algumas reflexões objetivando esse suporte metodológico da aplicação do Jamboard em sala virtual e dinâmica onde os alunos recebem explanações sobre as e-atividades que devem realizar, individualmente ou em grupo, que estão centradas nos alunos para que possam contribuir, discutir, inovar, interpretar e partilhar conhecimento.

Neste contexto didático, o aprendizado tem como alvo e-atividades de construção de conhecimento centradas no aluno no ambiente escolar, o papel dos meios de comunicação nesse sistema coloca os professores como organizadores das situações de ensino, enquanto o aluno é o construtor de seu conhecimento próprio, em escala individual e/ou grupal, reflexivo e crítico do que foi absorvido. A construção do conhecimento passa assim a ser mediada pelo 
docente, que atua como um problematizador ou um facilitador, não apenas um transmissor de conhecimento (BACICH; TANZI NETO; TREVISANI, 2015).

Nos critérios baseados por Moreira, Henriques e Barros (2020), observou-se que alguns deles devem ser considerados, na hora de elaborar uma e-atividade numa perspectiva integradora e motivadora no processo de ensino e aprendizagem destas atividades como estimular a aprendizagem autônoma, estimular a colaboração no espaço de aprendizagem virtual, promover um papel ativo do aluno e sua interação com o professor.

Essa sequência de passos para o processo de ensino e aprendizagem consiste em um processo dinâmico, que envolve a personalidade do aluno para aquisição ou modificação do conhecimento e seu desenvolvimento de competências fundamentais, a uma avaliação adequada, ao ponto de se ir adaptando aos resultados decorrentes do processo de autoavaliação.

As estratégias didáticas, que são técnicas utilizadas pelos professores com o objetivo de ajudar o aluno a construir seu conhecimento, divididas em processos, fazem estimular, colaborar, inovar, processar, promover e interagir através do uso da ferramenta Jamboard.

Essas estratégias são essenciais para extrair a melhor interação dos alunos, ajudandoos a adquirir e a compreender o conteúdo que foi discutido, em sala de aula virtual, e assim socializar o grupo, propiciando uma interação e uma construção colaborativa de conhecimentos da TIC em que se fundamenta no desenvolvimento da e-atividade no ambiente virtual de aprendizagem interativo, colaborativo e investigativo no processo do desenvolvimento do pensamento crítico.

\section{Processo de ensinar e aprender "online” com a ferramenta Jamboard}

A dinâmica da ferramenta Jamboard, nos cursos, é focada no processo de ensinar e aprender fazendo, valorizando a autonomia do aluno, no sentido de vivenciar estratégias didáticas usando TIC e instigar a exploração de recursos para potencializar o processo de ensino e aprendizagem na área do conhecimento e/ou unidade curricular e/ou conteúdo abordado.

O processo de avaliação da aprendizagem é um ponto bastante discutido e estudado na educação. "Nesta perspectiva, a avaliação da aprendizagem é um mecanismo subsidiário do planejamento e da execução. É uma atividade subsidiária e estritamente articulada com a 
execução" (LUCKESI, 2014, p. 161). No ensino online, no contexto de ensino remoto, essa preocupação é maior para ter mecanismos eficientes para realizar uma avaliação da aprendizagem adequada e real, que não seja apenas somativa, mas principalmente formativa e processual, implicando na participação contínua dos alunos em todos os momentos síncronos e assíncronos.

A avaliação do processo de ensino e aprendizagem deve ser realizada de forma contínua, cumulativa e sistemática com o objetivo de diagnosticar a situação da aprendizagem de cada aluno, em relação ao planejamento curricular, para isso apresentam-se as seguintes funções básicas: informar sobre o domínio da aprendizagem; indicar os efeitos da metodologia utilizada; revelar consequências da atuação docente; informar sobre a adequabilidade de currículos e programas; realizar feedback dos objetivos e planejamentos elaborados.

\section{Estratégia metodológica}

O método de pesquisa utilizado é de procedimento histórico, para compreender as estruturas das e-atividades realizadas na utilização do mural interativo nos momentos síncronos e assíncronos. Pesquisa qualitativa, do tipo estudo de caso. Parte-se do pressuposto de que a utilização do mural interativo online Jamboard contribui para o desenvolvimento de um processo dinâmico de transformação das práticas docentes com seus alunos, e a utilização da plataforma "Classroom” para postagem dos materiais didáticos, nas atividades assíncronas e avaliações e fórum de dúvidas.

As soluções, até então disponíveis com a ferramenta Jamboard em suas aulas, são apresentadas por videoconferência no Google Meet para todos os alunos, assim os professores que buscam novas mudanças podem romper com a educação tradicional e conectar-se ao mundo do conhecimento e das TIC, auxiliando o aluno a colaborar, inovar, promover, interagir e relacionar os dados para o convívio social.

Esta pesquisa também se configura como um estudo etnográfico. Neste sentido, Angrosino (2009) nos apresenta que "O objetivo dos etnometodólogos tem sido explicar como o sentido de realidade de um grupo é construído, mantido e transformado" (ANGROSINO, 2009, p. 25). Assim sendo, a pesquisa utiliza também a etnografia como fator importante do estudo, pois é um dos determinantes do conhecimento que será obtido 
por ela. Segundo Laville e Dionne (1999, p. 155) "a denominação refere-se evidentemente ao estudo, talvez o de uma pessoa, mas também o de um grupo, de uma comunidade, de um meio, ou então fará referência a um acontecimento especial”, tendo em vista que o estudo busca a interatividade dos alunos no uso da tecnologia digital e no sistema interativo nos momentos síncronos e assíncronos.

O ensino remoto emergencial se dá por meio da realização de práticas pedagógicas, por TIC e nos normativos da instituição que embasam as ações de ensino, pesquisa e extensão, que possibilitem o desenvolvimento dos objetivos de aprendizagem expressos nos Planos/Projetos Pedagógicos de Curso (PPC).

As atividades realizadas no momento remoto são consideradas como efetivo trabalho escolar, e a carga horária trabalhada remotamente é utilizada para a substituição da carga horária presencial, conforme disposto nas diretrizes do MEC e institucionais estabelecidas em resoluções e em conformidade com a legislação vigente. A medida visa promover o ensino e a aprendizagem vinculado diretamente com os alunos, reduzindo o seu impacto no ensino presencial.

Por meio do ensino remoto emergencial, em uma perspectiva de retorno gradual, enquanto durar a pandemia do Coronavírus, narram-se as vivências históricas dos envolvidos no processo, no ensino remoto, que se constituem como um momento ímpar para toda a comunidade acadêmica, em suas atividades de ensino das unidades curriculares, em especial dos cursos técnicos envolvidos. O aplicativo do G-suíte for Education é utilizado como plataforma de mediação tecnológica digital do processo de ensino e aprendizagem, complementando a plataforma SIGAA $^{9}$ já utilizada pela instituição.

Foi utilizado o aplicativo WhatsApp para criação de um grupo com o nome da disciplina para comunicação rápida, principalmente nos momentos de atividades assíncronas e para também postar os materiais em PDF utilizamos a plataforma Classroom, possibilitando a mediação do professor e aluno.

Para coleta de informações, foram utilizados os relatos dos alunos, na forma escrita, elaborados no Google formulários e documentos anexados pelos alunos, tais como avaliações, autoavaliações, trabalhos realizados, atividades construídas e desenvolvidas pelos alunos.

\footnotetext{
${ }^{9}$ Sistema Integrado de Gestão de Atividades Acadêmicas da Instituição de Ensino, para registros das notas, frequências, conteúdos
}

Revista Devir Educação, Lavras-MG. Edição Especial, p.206-226, Set./2021. 
As atividades previstas no planejamento foram postadas, semanalmente, no Classroom, com instruções das atividades assíncronas e arquivo em PDF, além disso, a plataforma disponibiliza um espaço para postagens de dúvidas e fóruns de discussões e um tutorial da ferramenta Jamboard para consulta.

$\mathrm{O}$ ambiente em que se deu a pesquisa foi o Instituto Federal de Alagoas (IFAL) nos cursos de Eletrotécnica e Enfermagem, respectivamente, em que os autores ministraram aulas, salienta-se que as atividades foram desenvolvidas com turmas dos cursos subsequentes, do $2^{\circ}$ período de Eletrotécnica e $3^{\circ}$ período de Enfermagem, cujo universo da pesquisa foram 37 alunos.

A estrutura detalhada geral foi dividida em 5 encontros, sendo distribuídos em forma de planejamento do ensino remoto que foram aplicados no tratamento de temáticas envolvendo a ferramenta Jamboard com os conteúdos das unidades curriculares dos cursos na abordagem das suas ementas. Os encontros foram desenvolvidos através da metodologia de aprendizagem no estudo de caso no uso de ferramentas colaborativas e interativas.

Por fim, percebeu-se a importância da Instituição de Ensino, no contexto de aulas remotas, de deixar de lado os paradigmas arcaicos, em que muitos ainda encontravam-se, para pautar-se e acompanhar-se das mudanças ocorridas no seio da sociedade que a cerca, adotando os recursos tecnológicos que possui, tais como computadores, tablets, smartphone e internet banda larga para auxiliar na aprendizagem significativa dos seus alunos, proporcionando a formação de cidadãos mais participativos, críticos e atuantes na sociedade em que vive.

\section{Planejamento das e-atividades e descrição dos momentos online}

$\mathrm{O}$ roteiro do planejamento é baseado em uma sequência didática (SD), assim, o planejamento passa a ter um papel importante, numa e-atividade didática, utilizando o uso da ferramenta em sala de aula virtual síncrona e assíncrona, com o objetivo de mostrar algumas práticas escolares em sala de aula por meio de SD, percebe-se assim, a necessidade de um novo ensino para as unidades curriculares, realizando um novo repensar da prática enquanto professores, na "pedagogia do discurso", tratando-se de construir uma visão de conteúdo voltada para a formação de um cidadão contemporâneo da sua realidade social.

Apresenta-se abaixo o roteiro de como deve se dar o planejamento das e-atividades: 
- Estudos individuais e em grupo pelos alunos para solucionar o problema com a leitura e uso de artigos científicos;

- No encontro em grupo deve-se discutir a situação-problema à luz dos novos conhecimentos adquiridos com o estudo individual;

- $\quad$ Para o encontro será disponibilizado um link para ser realizada as atividades pela ferramenta Jamboard, identificando a problemática das e-atividades;

- Cada aluno deverá fazer um relatório do seu estudo individual com os principais pontos vistos no item anterior estudado, que ficou sob sua responsabilidade e apresentar no estudo em grupo;

- Na reunião do grupo deverá ser definida a solução para a situação-problema, justificando a escolha, que deve ser apresentada a todos da turma para debate.

No quadro 1 é apresentada a descrição detalhada de cada etapa da sequência das atividades, como também são indicados quais os encontros, objetivos e o tempo destinado a esses encontros.

Quadro 1 - Atividades realizadas nas aulas síncronas - Maceió - 2020.

\begin{tabular}{|c|c|c|c|c|}
\hline Encontro $^{10}$ & Atividades & Objetivos/Métodos & Duração & Cursos \\
\hline $\begin{array}{l}\text { Apresentação } \\
\text { da ferramenta a } \\
\text { turma. }\end{array}$ & $\begin{array}{l}\text { Uso da ferramenta Jambord } \\
\text { online. }\end{array}$ & $\begin{array}{l}\text { Conhecer a ferramenta } \\
\text { móvel Jamboard e como } \\
\text { usá-la na disciplina. }\end{array}$ & $100 \mathrm{~min}$ & $\begin{array}{l}\text { Técnico } \\
\text { Eletrotécnica }\end{array}$ \\
\hline $\begin{array}{l}\text { Divisão dos } \\
\text { grupos e a } \\
\text { realização da } \\
\text { atividade } \mathbf{- 1}\end{array}$ & $\begin{array}{l}\text { e-atividade - } 1 \text { Pesquisa sobre } \\
\text { os tipos de Fonte de Energia - } \\
\text { segue link: } \\
\text { https://jamboard.g } \\
\text { oogle.com/d/1ObP } \\
\text { PjgAnmR5PacQY } \\
\text { 1pjY6Z88afG53d } \\
\text { GkY4W1ScHJXM } \\
\text { 4/edit?usp=sharing. }\end{array}$ & $\begin{array}{l}\text { Conceituar os tipos de } \\
\text { fontes alternativas com uso } \\
\text { da ferramenta Jamboard. }\end{array}$ & $100 \mathrm{~min}$ & $\begin{array}{l}\text { Técnico } \\
\text { Eletrotécnica }\end{array}$ \\
\hline $\begin{array}{l}\text { Apresentação } \\
\text { da ferramenta a } \\
\text { turma. }\end{array}$ & $\begin{array}{l}\text { Uso da ferramenta Jambord } \\
\text { online. }\end{array}$ & $\begin{array}{l}\text { Conhecer a ferramenta } \\
\text { móvel Jamboard e como } \\
\text { usá-la na disciplina. }\end{array}$ & $100 \mathrm{~min}$ & $\begin{array}{c}\text { Técnico em } \\
\text { Enfermagem }\end{array}$ \\
\hline
\end{tabular}

${ }^{10}$ Dia da aula seguindo planejamento/cronograma da disciplina pelo sistema remoto emergencial.

Revista Devir Educação, Lavras-MG. Edição Especial, p.206-226, Set./2021. 


\begin{tabular}{|c|c|c|c|c|}
\hline $\begin{array}{l}\text { Divisão dos } \\
\text { grupos e a } \\
\text { realização da } \\
\text { atividade -1 }\end{array}$ & 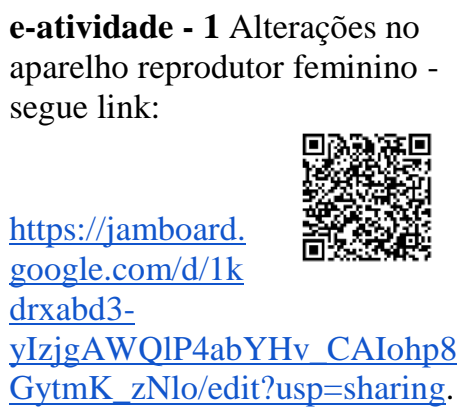 & $\begin{array}{l}\text { Conceituar os tipos de } \\
\text { aparelho reprodutivos } \\
\text { feminino com uso da } \\
\text { ferramenta Jamboard. }\end{array}$ & $100 \mathrm{~min}$ & $\begin{array}{c}\text { Técnico em } \\
\text { Enfermagem }\end{array}$ \\
\hline
\end{tabular}

Fonte: Autoria própria (2020).

\section{Resultados e discussões}

Ao longo desta seção destaca-se e descreve-se as experiências vividas pelos autores do estudo e os diálogos entre os alunos nas e-atividades que aconteceram durante as aulas síncronas e assíncronas, nos cursos envolvidos, devido ao período da pandemia.

O conteúdo foi disponibilizado com uma semana de antecedência, via sistema acadêmico da Instituição e pela plataforma Classroom, para que os alunos lessem e anotassem as possíveis dúvidas e suas contribuições sobre o assunto.

As e-atividades construídas pelos autores apontaram uma sequência didática de aulas diante de um processo de ensino das unidades curriculares trabalhadas remotamente. A interação dos alunos, com as questões previstas nos roteiros propostos e ao longo das aulas, foi mediada pelos professores dos cursos técnicos em estudo, sendo alguns conteúdos acrescentados durante as aulas através desta mediação. Como em todo esforço de aprendizagem produzir conteúdo à distância, em qualquer formato, tem uma "curva de aprendizagem", e precisa-se estar disposto a passar por ela, como sabe-se, as mudanças organizacionais são muitas vezes difíceis e implicam em enormes desafios institucionais, pessoais e coletivos de adaptação, de mudança, de flexibilidade e inovação.

Nesta pesquisa foi apresentada a ferramenta e como utilizá-la, através de seu tutorial, para a turma, e logo depois a realização da divisão dos grupos para a realização das eatividades. No contexto da metodologia ativa, buscou-se discutir com os alunos os estudos das unidades curriculares, seguindo a ementa de cada curso, e suas contribuições para o desenvolvimento das e-atividades. Cada grupo ficou com um "painel em branco interativo para escrever as respostas" e assim os professores fizeram suas devidas orientações 
virtualmente, para desenvolver a e-atividade colaborativamente ou individual, enriquecendo de acordo com a criatividade de cada turma, assim trazendo a resposta do enunciado da eatividade dos/as alunos/as, detalhadas nas Figuras 3 e 4, como conceitos dos assuntos, desenhos, entre outros, incentivando assim a autonomia, a criatividade, a pesquisa e a colaboração dos alunos.

Na e-atividade 1, realizada pelos alunos do curso de Eletrotécnica, o professor da disciplina Geração de Transmissão e Distribuição de Energia (GTDE), previamente colocou 7 temas para que eles pesquisassem sobre a produção de energia e elaborassem um resumo do tema escolhido por eles. Para a realização da e-atividade 1 foi utilizada a ferramenta Jamboard como avaliação diagnóstica, formativa e somativa, por exemplo: "Tipos de Fontes", "Conceitos", "Vantagens" e "Características das fontes". Entretanto, a escolha de uma pergunta, como está estruturada, permitiu observar outras habilidades dos alunos, como a sua capacidade em resumir e criar relações sem a indicação direta do professor, utilizando um quadro interativo para escrever seu resumo e finalizar a e-atividade.

As e-atividades disponibilizadas na forma escrita e suas apresentações mostrou-se que houve uma preocupação de contextualização do ensino que deu sentido e (re)significado aos conteúdos abordados pelos professores no momento online. Assim, seguem os detalhes que foram apresentados no quadro 1: os enunciados das questões apresentadas com seus devidos links ou QR - Code elaborados pelos professores e o seu devido tempo das e-atividades a serem trabalhadas pelos alunos durante as aulas, seja no curso técnico em Eletrotécnica ou Enfermagem, tendo como subsídio, para sua explicação, o conteúdo das unidades curriculares e os roteiros, os conhecimentos prévios e os resultados obtidos a partir das eatividades experimentais propostas nos roteiros.

A partir da discussão da importância da interatividade, através da ferramenta Jamboard na construção e na produção de um quadro interativo, foi proposto que realizassem a e-atividade que possibilitou aos alunos a aprendizagem e a utilização de frames, até então, nunca utilizados por eles. Portanto, foi um processo produtivo de aprender a utilizar um recurso novo, entendendo as suas funcionalidades, a exemplo de como inserir uma imagem, como escrever uma mensagem no Jamboard. Assim, todos puderam colaborar e realizar um trabalho em equipe ou individual na utilização da ferramenta nas aulas remotas, além disso, foi fundamental para dinamizar os recursos didáticos, produzindo aulas motivadoras para os alunos e proporcionando uma aprendizagem significativa.

Revista Devir Educação, Lavras-MG. Edição Especial, p.206-226, Set./2021. 


\section{Experiências vivenciadas na disciplina GTDE}

Nesta seção um dos autores traz seu relato de experiência, deste artigo, com os alunos do terceiro período do curso de eletrotécnica na disciplina de GTDE, com carga horária de 80 horas, as aulas ocorrendo sempre às segundas-feiras, com duas 2 aulas por semana. A turma contava com 20 alunos matriculados, mas participando efetivamente das aulas síncronas somente 15, os quais foram instruídos previamente acerca do uso da ferramenta Jamboard e de suas potencialidades, os demais não justificaram os motivos da não participação das aulas.

Assim, segue na Figura 3, a e-atividade realizada pelo aluno B de Eletrotécnica.

Nome: B

1. Energia Solar fotovoltaica

A energia do Sol pode ser utilizada para produzir eletricidade pelo efeito fotovoltaico, que consiste na conversão direta da luz solar em energia elétrica.

A energia do Sol é propagada através do espaço na forma de radiação eletromagnética. Essa radiação é composta por ondas de diferentes frequências/comprimento de onda.

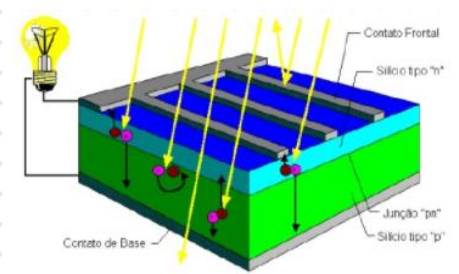

OK.

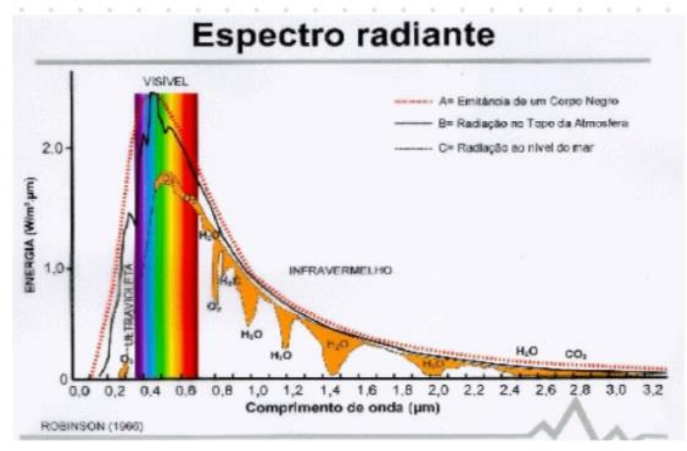

THE ELECTROMAGNETIC SPECTRUM

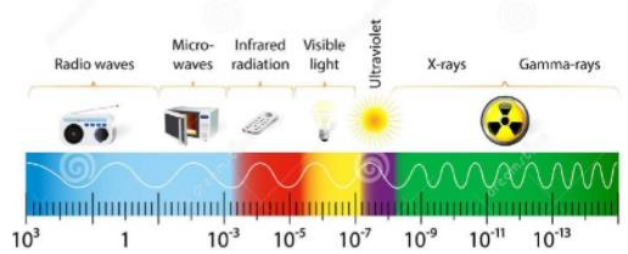

Figur

a 3 -

Uso

da ferramenta Jamboard com o aluno construindo e-atividades - Eletrotécnica.

Fonte: Login do professor, adaptado Jamboard (2021).

Nessa perspectiva observou-se, como experiência docente, no uso de metodologia ativa, com a ferramenta Jamboard, através da análise da e-atividade, nas aulas síncronas, que o método foi bem recebido pelos alunos, que se sentiram motivados na participação nesse momento de pandemia da Covid-19. Apesar do interesse e da participação deles, alguns alunos demonstraram falta de habilidades com a ferramenta online, mas aos poucos eles

Revista Devir Educação, Lavras-MG. Edição Especial, p.206-226, Set./2021. 
foram se adequando com a ferramenta. Apresenta-se alguns depoimentos expressados por eles: é muito bom aprender brincando; o tempo passou e não percebemos; a aula de hoje foi muito motivadora. O uso de TIC e redes sociais devem ser vistos como propulsores da criação de novas relações com a informação, com o tempo, com o espaço, consigo mesmo e com os outros (SOUZA, 2020).

O processo de formação apresentou condições favoráveis para o professor construir conhecimentos com seus alunos, sobre a ferramenta utilizada Jamboard, como experiência, no uso de metodologias ativas e como entender e integrar estas na sua prática pedagógica, através da análise das e-atividades que permitiram configurar diferentes cenários formativos e proporcionaram uma aprendizagem mais significativa.

\section{Experiências vivenciadas na disciplina enfermagem em saúde da mulher}

Nesta seção um dos autores traz seu relato de experiência, com os alunos do terceiro período do curso técnico em enfermagem, na unidade curricular Enfermagem e saúde da mulher, com carga horária de 80 horas, as aulas ocorrendo de forma modular, com 5 horas de aulas diárias, divididas em momentos síncronos e assíncronos. A turma contava com 22 alunos matriculados, todos participando efetivamente das aulas, os quais foram instruídos previamente acerca do uso da ferramenta Jamboard e de suas potencialidades. Na e-atividade realizada no curso técnico em enfermagem a turma foi dividida em grupos cada um com um quadro interativo com estudos de casos relacionados às alterações no aparelho reprodutor feminino para os alunos pesquisarem sobre qual o problema, sinais e sintomas e como resolver o problema, podendo também acompanhar os estudos de caso nos frames dos colegas. Assim, segue na Figura 4, a e-atividade realizada pelo grupo 1. 


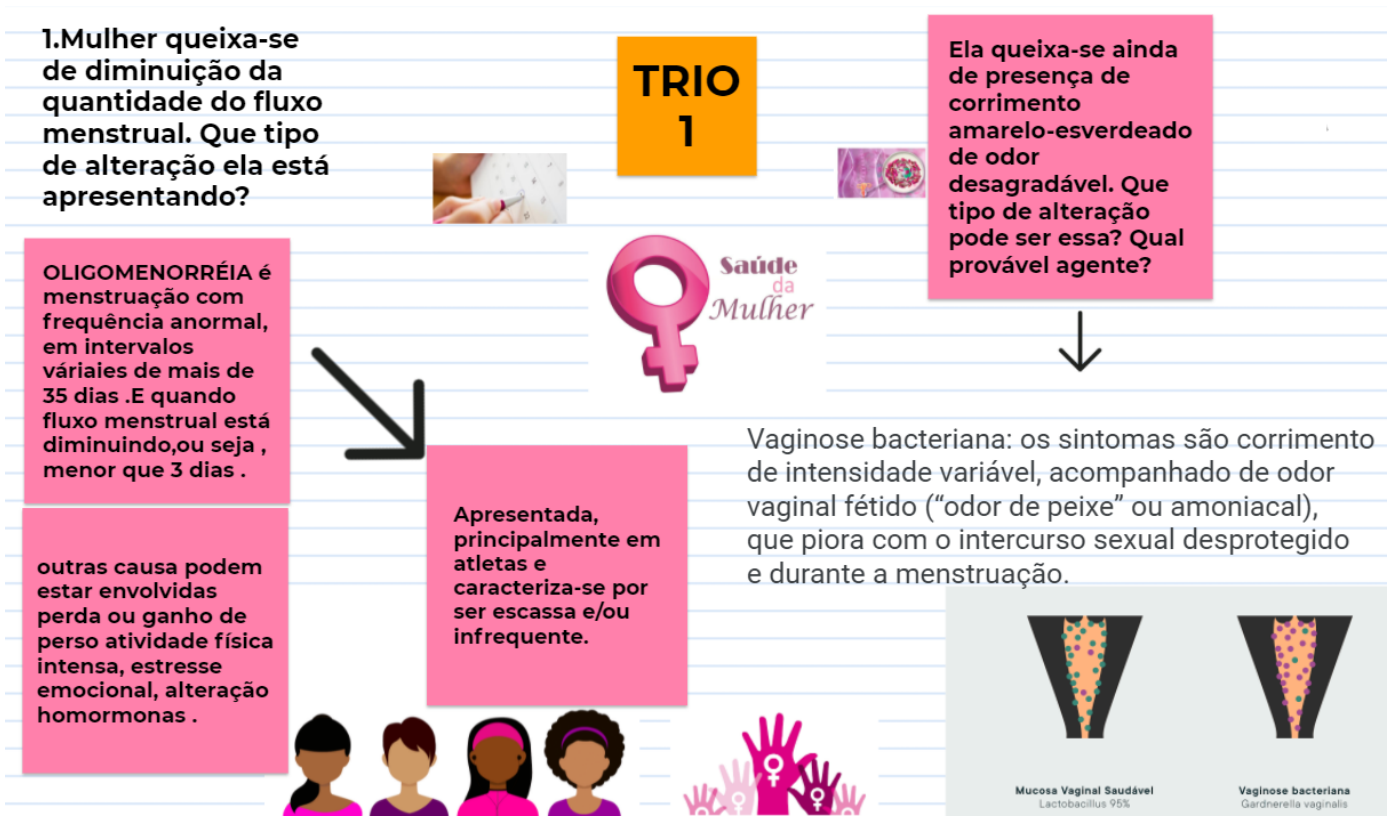

Figura 4 - Uso da ferramenta Jamboard com os alunos e-atividades - Enfermagem Fonte: Login do professor, adaptado Jamboard (2021).

Os alunos foram estimulados a partir das e-atividades, através de estudo de caso, na formulação de soluções aos problemas apresentados, bem como enriquecerem as suas construções com imagens, vídeos e o que fossem pertinentes ao contexto apresentado. Como houve uma apresentação prévia da ferramenta, os alunos conseguiram desenvolver a eatividade, mas alguns tiveram alguma dificuldade devido a ferramenta ser nova para eles, entretanto, observou-se que ao final conseguiram interagir satisfatoriamente com a ferramenta.

No encerramento das e-atividades, os professores envolvidos dialogaram com os seus respectivos alunos, na busca de diagnosticar como foram os momentos síncronos e assíncronos e fizeram uma avaliação informal de suas impressões iniciais e finais de todo o processo ao longo do período.

As práticas com a ferramenta Jamboard foram interativas e os resultados das eatividades dos momentos online, aqui apresentados, resgataram o envolvimento dos professores e alunos no saber da vivência experimentada com a ferramenta, a fim de problematizar os conhecimentos dos envolvidos acerca da situação-limite que foi imposta na disseminação pela covid-19, no que tange às práticas educativas - ensino remoto.

\section{Considerações finais}

Revista Devir Educação, Lavras-MG. Edição Especial, p.206-226, Set./2021. 
Em relação aos resultados dessa experiência, vivenciada pelos professores, verificouse a contribuição para a compreensão das condições materiais e subjetivas de permanência e de desenvolvimento do papel social dos alunos dos cursos envolvidos, conforme verificado, quanto mais interação entre os pesquisadores e os alunos mais houve contribuição com a ferramenta usada em estudo, mais possibilidades terão de explorá-las nas atividades online, organização de estudos e adequação do tempo. Além disso, pode auxiliar os alunos a formularem novos objetivos e criarem formas de estudos que façam sentido para cada um, além de possibilitar o compartilhamento de conhecimentos e a troca de experiências entre os pares.

Através das experiências, acompanhamentos e orientações das aulas pelos autores envolvidos na pesquisa, vivenciadas por eles, buscou-se trazer práticas construídas nos momentos síncronos e assíncronos nos dois cursos de Eletrotécnica e Enfermagem, a fim de compartilhar esses desafios e essas práticas que trouxeram conhecimentos e envolvimento dos participantes nas aulas remotas. É notável que as metodologias envolvidas no processo de ensino e aprendizagem dessas ações, trouxeram espontaneidade dos participantes no transcorrer da utilização da ferramenta.

O desenvolvimento desta pesquisa contribuiu para o desenvolvimento do papel profissional dos pesquisadores, modificando a forma de atuar em sala de aula, buscando realizar uma parceria com os alunos, transformando-se em mediador do processo de ensino e aprendizagem.

Este artigo objetivou relatar a experiência dos autores, em aulas remotas com a aplicação de metodologia ativa, no caso, o Jamboard no período de pandemia comparando experiências coletadas por meio de e-atividades no processo de ensino e aprendizagem. Além disso, buscou também apresentar um convite a um aprofundamento das questões aqui explicitadas, tendo em vista as contribuições que essas podem exercer na consolidação das aulas ministradas remotamente e a interação delas na utilização de ferramentas em aulas síncronas e assíncronas, bem como no fomento da formação de futuros professores com o uso de TIC.

Considerando o cenário do ensino remoto provocado pela crise de saúde mundial sem precedentes, os princípios básicos que um professor deve conhecer para o design de um ambiente online, em relação, sobretudo, à sua organização, seleção de recursos, planejamento, 


\section{OO DEVIR EDUCAÇÃO}

ISSN: 2526-849X

construção e avaliação de atividades de aprendizagem síncronas com o uso do Jamboard, nos permitiu viajar numa intencional atitude de reencantamento e virtualização da realidade educacional, ingredientes necessários à nossa condição de educador, porém estavam perdidos com a sociedade da industrialização e seu método intelectual de instituição.

Em suma, a amplitude da temática aqui abordada trouxe um dos principais objetivos da pesquisa, que foi aprender a ensinar e a colaborar remotamente utilizando estratégias a partir do estudo de ferramentas online, construindo através das tecnologias digitais embasadas e justificadas pelo "novo normal" em uma sala de aula a distância, em especial Jamboard, que proporcionou aos alunos e professores um enriquecimento de aulas remotas, trazendo novos desafios de trabalhar o conhecimento de forma colaborativa, interativa e participativa, favorecendo uma aprendizagem interativa e multidisciplinar, de forma a mostrar que é possível usar uma contextualização diferenciada no ensino.

\section{Referências}

AUSUBEL, David Paul. Educational psychology: a cognitive view. New York: Holt, Rinehart \& Winston, 1968.

ANGROSINO, Michael. Etnografia e observação participante: coleção pesquisa qualitativa. 1 ed. Porto Alegre: Bookman Editora, 2009.

BACICH, Lilian; TANZI NETO, Adolfo; TREVISANI, Fernando de Mello. Ensino híbrido personalização e tecnologia na educação. Porto Alegre: Penso, 2015.

LAVILLE, Christian; DIONNE, Jean. A construção do Saber (manual de metodologia em ciências humanas). Porto Alegre, RS: Editora Artes Médicas Sul Ltda; Belo Horizonte: Editora UFMG, 1999.

LUCKESI, Cipriano Carlos. Avaliação da aprendizagem escolar: estudos e proposições. 1. ed. São Paulo: Cortez editora, 2014.

MARTINS, Vivian; ALMEIDA, Joelma. EDUCAÇÃO EM TEMPOS DE PANDEMIA NO BRASIL: saberes fazeres escolares em exposição nas redes e a educação on-line como perspectiva. Revista Docência e Cibercultura Redoc, Rio de Janeiro, v. 4 n.2 p. 215 maio/Ago 2020.

MOREIRA, José António Marques; HENRIQUES, Susana; BARROS, Daniela. Transitando de um ensino remoto emergencial para uma educação digital em rede, em tempos de pandemia. Dialogia, São Paulo, n. 34, p. 351-364, jan./abr. 2020. 
PORTARIA No 1303, DE 19 DE MARÇO DE 2020, Disponível em: <https://www2.ifal.edu.br/medidas-administrativas-de-combate-ao-coronavirus/arquivosmedidas-administrativas/portaria-suspende-o-atendimento-no-ifal> . Acesso em 18.03.2021.

PRESIDENTE DO CONSELHO SUPERIOR do Instituto Federal de Alagoas - IFAL, órgão de caráter consultivo e deliberativo da Administração Superior, no uso de suas atribuições conferidas pelo $\S 3^{\circ}$, do Art.10, da Lei $n^{\circ} 11.892$, de 29/12/2008, publicada no DOU de 30/12/2008, nomeado pelo Decreto Presidencial de 10/6/2019, publicado no DOU no 111 , Seção 02, de 11/6/2019, resolução de $\mathrm{n}^{\circ} 50$ / 2020. Disponível em: https://www2.ifal.edu.br/noticias/ifal-retoma-atividades-academicas-por-meio-de-ensinoremoto/resolucao-ndeg-50-2020-aprova-as-diretrizes-para-o-ensino-remoto-emergencial-noifal.pdf. Acesso em: 11.04.2021

Resolução $\mathrm{n}^{\circ}$ 50/2020, que trata das diretrizes institucionais para o ensino remoto emergencial, e a Deliberação $n^{\circ}$ 58/2020. Disponível em: <https://www2.ifal.edu.br/noticias/ifal-retoma-atividades-academicas-por-meio-de-ensinoremoto/resolucao-ndeg-50-2020-aprova-as-diretrizes-para-o-ensino-remoto-emergencial-noifal.pdf>. Acesso em 18.03.2021.

SALMON, Gilly. E-actividades. El factor clave para una formación en línea activa. Barcelona: Editorial UOC, 2004.

SOUZA, Elmara Pereira de. Educação em tempos de pandemia: desafios e possibilidades. Cadernos de Ciências Sociais Aplicadas, Ano XVII Volume 17 No 30 jul./dez. 2020.

Recebido em: 30/06/21

Aprovado em: 30/07/21

Revista Devir Educação, Lavras-MG. Edição Especial, p.206-226, Set./2021. 